\title{
STUDY OF VARIOUS PARAMETERS THAT INFLUENCE THE CONTENT OF EXHALED BREATH CONDENSATE USED IN THE DIAGNOSIS OF GAS- TROESOPHAGEAL REFLUX DISEASE
}

\author{
Michal GReguš *1,2, Pavol ĎurČ ${ }^{1,2}$, Júlia LaČnÁ ${ }^{1,2}$, František Foret ${ }^{1,3}$, ANd Petr \\ KUBÁŇ ${ }^{1,2,3}$ \\ ${ }^{1}$ Department of Bioanalytical Instrumentation, CEITEC Masaryk University, Veveři 97, 60200 Brno, CZECH \\ REPUBLIC \\ ${ }^{2}$ Department of Chemistry, Masaryk University, Kotlářská 267/2, 61137 Brno, CZECH REPUBLIC \\ ${ }^{3}$ Department of Bioanalytical Instrumentation, Institute of Analytical Chemistry of the Czech Academy of \\ Sciences, v.v.i., Veveři 97, 60200 Brno, CZECH REPUBLIC
}

\begin{abstract}
In this work, various parameters that influence the ionic content and $\mathrm{pH}$ of exhaled breath condensate in terms of the noninvasive diagnosis of gastroesophageal reflux disease were studied. Exhaled breath condensate samples were collected using a miniature and inexpensive sampling device. Capillary electrophoresis with contactless conductometric detection was used to monitor the ionic content of exhaled breath condensate. Background electrolyte composed of $20 \mathrm{mM}$ of 2-(N-Morpholino)ethanesulfonic acid, $20 \mathrm{mM}$ of L-Histidine, $2 \mathrm{mM}$ of 18-Crown- 6 and $30 \mu \mathrm{M}$ of cetyltrimethylammonium bromide facilitated the rapid separation of anions and cations, both in less than 2 minutes. The possibility of contamination of the exhaled breath condensate by saliva is discussed in detail. The day-to-day repeatability $(n=5)$ of the ionic content and $\mathrm{pH}$ of the exhaled breath condensate was studied and was satisfactory, reflecting mainly the physiological variability.
\end{abstract}

Keywords: capillary electrophoresis, exhaled breath condensate, ionic analysis, $\mathrm{pH}$, gastroesophageal reflux disease

\section{Introduction}

Gastroesophageal reflux disease (GERD) is a disease caused by the backflow of gastric contents into the esophagus due to the failure of physiological antireflux mechanisms and can lead to symptoms such as a chronic cough, globus sensation, laryngitis, pharyngitis, rhinosinusitis, otitis media, bronchial asthma, chronic obstructive pulmonary disease, sleep apnea and noncardiac chest pain $[1,2]$. Currently, no suitable, non-invasive diagnostic method for GERD is applicable in clinical practice. Nowadays, the gold standard with regard to the diagnosis of GERD is a 24-hour multichannel intraluminal impedance-pH technique (MII-pH) that is rather invasive [3]. Non-invasive sampling is becoming more important. Exhaled breath condensate (EBC) as one of several noninvasive samples can be easily obtained by the cooling and subsequent condensation of exhaled breath. The EBC is composed mainly of water, however, it also contains volatile and non-volatile compounds (inorganic ions, organic acids) that can be useful as biomarkers of various diseases [4].

The identification of ions in EBC samples is easily achieved by capillary electrophoresis (CE). The main ad-

\footnotetext{
*Correspondence: gregus@mail.muni.cz
}

vantage of this method is that it is able to cope with a minute volume of samples and analyses are often very rapid. Another parameter that is often used to diagnose GERD is $\mathrm{pH}$, measured by a conventional MII-pH probe, which is both invasive and costly. The $\mathrm{pH}$ can also be measured in collected samples of EBC [5] which is noninvasive and cheaper. Monitoring various parameters of EBC in patients suffering from symptoms of extraesophageal/gastroesophageal reflux disease is an attractive, simple and non-invasive approach that could be used as a surrogate for other, more invasive diagnostic methods. However, to obtain relevant results, various parameters that can affect the results such as sampling procedures, effects of food and drinks and the intraday variability of individuals have to be studied prior to the use of EBC sampling in diagnostics.

\section{Experimental}

\subsection{Instrumentation}

A purpose-built CE instrument was used for all CE analyses. The separation voltage was provided by a highvoltage power-supply unit (DX250, EMCO High Voltage, Sutter Creek, CA, USA). A custom-made contactless conductivity detector (C4D, Version 5.06, ADMET 


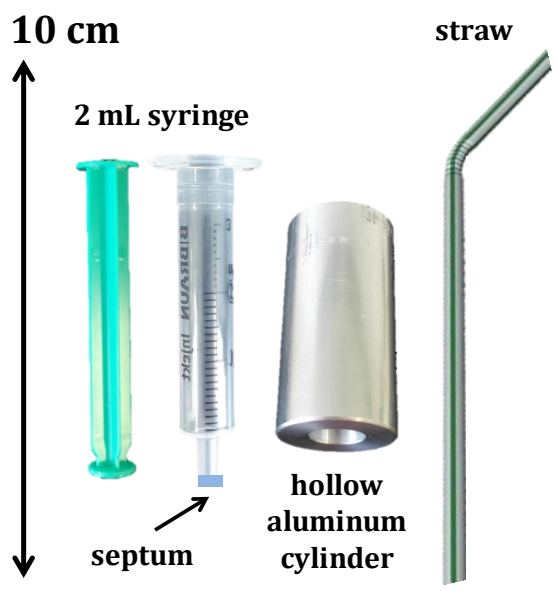

Figure 1: The photo of the components used to build a miniature EBC sampling device.

s.r.o., Prague, Czech Republic) operating at a frequency of $1.8432 \mathrm{MHz}$ and a voltage of $50 \mathrm{~V}_{\mathrm{p}-\mathrm{p}}$ using a 24-bit A/D converter (ORCA 2800, ECOM s.r.o., Prague, Czech Republic) was used to detect separated analytes and collect data. CE analyses were performed in fused-silica capillaries (inner diameter (ID) of $50 \mu \mathrm{m}$, outer diameter (OD) of $375 \mu \mathrm{m}$, total length of $40 \mathrm{~cm}$, effective length of $17 \mathrm{~cm}$, MicroQuartz GmbH, Munich, Germany). Injection of a standard solution and samples was performed hydrodynamically. Two Pt wires (OD of $0.5 \mathrm{~mm}$, length of $3 \mathrm{~cm}$, Advent Research Materials Ltd., Eynsham, England) were inserted into the electrolyte vials to serve as electrodes. All CE experiments were performed at ambient temperature.

To measure the $\mathrm{pH}$ of the EBC samples, $\mathrm{CO}_{2}$ present in these samples was removed by a stream of $\mathrm{N}_{2}$ gas (nitrogen generator, RP-ZE-N2L3000). The $\mathrm{pH}$ was measured using a $\mathrm{pH}$ microelectrode (MI-410 Microcombination $\mathrm{pH}$ Probe, Microelectrodes, Inc., Bedford, New Hampshire, USA) and pH-meter (Orion Star ${ }^{\mathrm{TM}}$ A111 pH Benchtop Meter, Thermo Fisher Scientific, Waltham, Massachusetts, USA).

EBC samples were collected from the volunteers using an EBC sampler previously developed by our group $[6,7]$. Briefly, the sampler for collection of EBC was constructed from a 2-mL syringe (B. Braun Melsungen AG, Melsungen, Germany) and a $5 \mathrm{~cm}$-long hollow aluminum cylinder (see Fig. 1) with an outer diameter (OD) of 2.5 $\mathrm{cm}$ and an inner diameter (ID) precisely matching the outer diameter of the syringe to facilitate efficient cooling of the walls. The cylinder was kept in a deep freezer at $-17^{\circ} \mathrm{C}$ and an insulation sleeve was used during collection to maintain the temperature for the whole duration of the sampling procedure. Another aim of this insulation sleeve was to prevent frostbite during collection of the sample. Straw (purchased from a local store) with an OD of $6 \mathrm{~mm}$ and wall thickness of $0.2 \mathrm{~mm}$ was used to exhale the air through the sampler. The end of the syringe was enclosed with a parafilm septum to avoid EBC loss.

\subsection{Chemicals}

All chemicals were of reagent grade, and deionized (DI) water was used for preparation and dilution of the stock solution. Stock solutions $(10 \mathrm{mM})$ consisting of inorganic anions and cations were prepared from their sodium and chloride salts $\left(\mathrm{NaCl}, \mathrm{NaNO}_{3}, \mathrm{NaNO}_{2}, \mathrm{Na}_{2} \mathrm{SO}_{4}, \mathrm{KCl}\right.$, $\mathrm{CaCl}_{2}, \mathrm{MgCl}_{2}$ ) with the exception of ammonium, the stock solution of which was prepared from ammonium fluoride (all from PLIVA-Lachema, Brno, Czech Republic). The stock solutions of anions from organic acids were prepared from lithium acetate dihydrate, lithium lactate, propionic acid and butyric acid (all from SigmaAldrich, Steinheim, Germany).

The background electrolyte (BGE) for CE measurements was prepared daily by diluting $100 \mathrm{mM}$ stock solutions of 2-(N-Morpholino)ethanesulfonic acid (MES), L-Histidine (His) and $100 \mathrm{mM}$ 18-Crown6 (all Sigma-Aldrich) to the required concentration. Hexadecyltrimethylammonium bromide (CTAB, Sigma-Aldrich) was prepared as $10 \mathrm{mM}$ stock solution in $5 \%$ acetonitrile and was added to the BGE to yield the final concentration of $30 \mu \mathrm{M}$.

\subsection{Capillary conditioning}

Prior to its first use, the separation capillary was preconditioned by flushing it with $0.1 \mathrm{M} \mathrm{NaOH}$ for 30 mins, DI water for 30 mins and BGE solution for 20 mins. Between two successive injections, the capillary was flushed with BGE solution for $1 \mathrm{~min}$. At the end of a working day, the capillaries were washed with DI water for 15 mins and stored in DI water overnight.

\section{Results and Analysis}

\subsection{EBC sampling procedure}

The collection of EBC consists of several steps: deep exhalation until the lungs were as empty as possible, followed by rapid inhalation (1-2 s) and finally gradual complete exhalation into the sampling device (8-10 s). This procedure was suggested by Almstrand et al. [8] and yielded the highest concentration of respiratory droplets and, therefore, the highest concentrations of non-volatile substances present in EBC. The volunteer was asked to exhale three times into the sampling device according to the proposed procedure. After the EBC sampling had been completed, the condensate from the syringe walls was wiped with the plunger of the syringe as far as the tip of the syringe and transferred to the sample vial for $\mathrm{CE}$ analysis. Often, only one exhalation $(30 \mu \mathrm{L}$ of the sample) was sufficient to obtain a sizable amount of EBC for $\mathrm{CE}$ analysis. During the wiping procedure, the condensate collected from the walls is naturally mixed and 


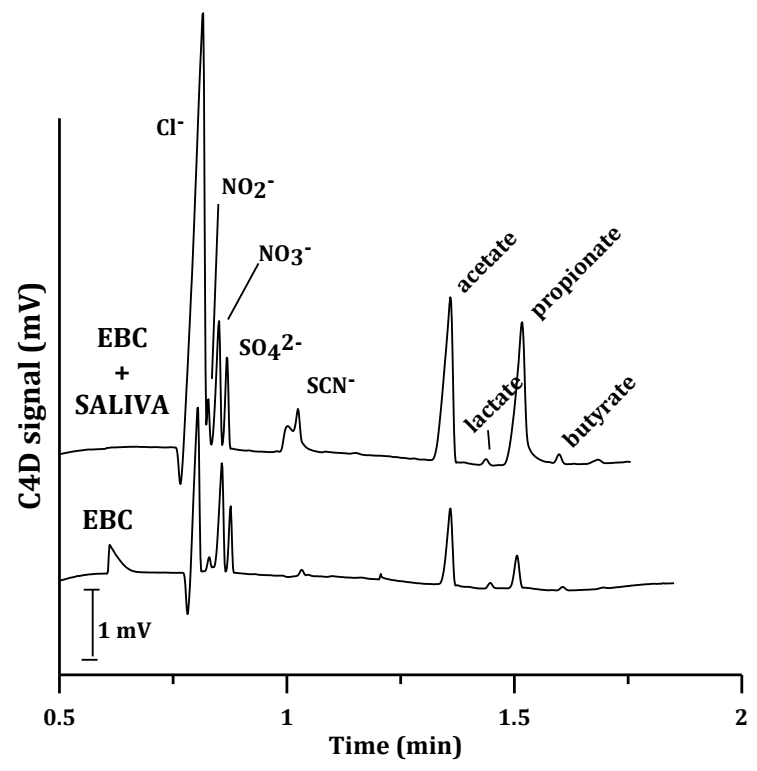

Figure 2: Anionic separation of an EBC sample and an EBC sample spiked with human saliva. BGE: $20 \mathrm{mM}$ MES/His, 2 mM 18-Crown-6, $30 \mu \mathrm{M}$ CTAB. HV: positive $+15 \mathrm{kV}, \mathrm{C} 4 \mathrm{D}$ detection. Injection: hydrodynamic for $30 \mathrm{~s}$ at a height of $10 \mathrm{~cm}$.

a representative EBC sample is thus obtained. To maintain the simplicity, low costs and wide availability of the components necessary for the EBC sampler, a saliva trap was not included. Therefore, one can occasionally expect interference from saliva droplets.

This can happen especially when sampling of long durations is applied or EBC is collected from patients with serious lung diseases and/or children. Nevertheless, saliva contamination is very rare and happened in ca. 1 in every 100 samples. Contaminated samples were easily identified and excluded from further investigations. Fig. 2 shows the CE separation of anions from two EBC samples; an EBC sample obtained from 3 deep exhalations $(\approx 100 \mu \mathrm{L}$ of $\mathrm{EBC})$ and the same EBC sample spiked with $1 \mu \mathrm{L}$ of human saliva (to simulate saliva contamination). The EBC sample spiked with saliva displayed a huge increase in the concentration of all anions which significantly exceeded the upper limits of concentrations found in healthy individuals or patients suffering from various lung diseases $[9,10]$. Another even more suitable indicator is the thiocyanate, normally present in human saliva [11] but not in EBC.

Cationic analysis of the same two samples (Fig. 3) exhibited the highest increase in sodium and potassium, again way above the normal levels as far as the concentrations of healthy people and sufferers are concerned. Other cations also exhibited increases.

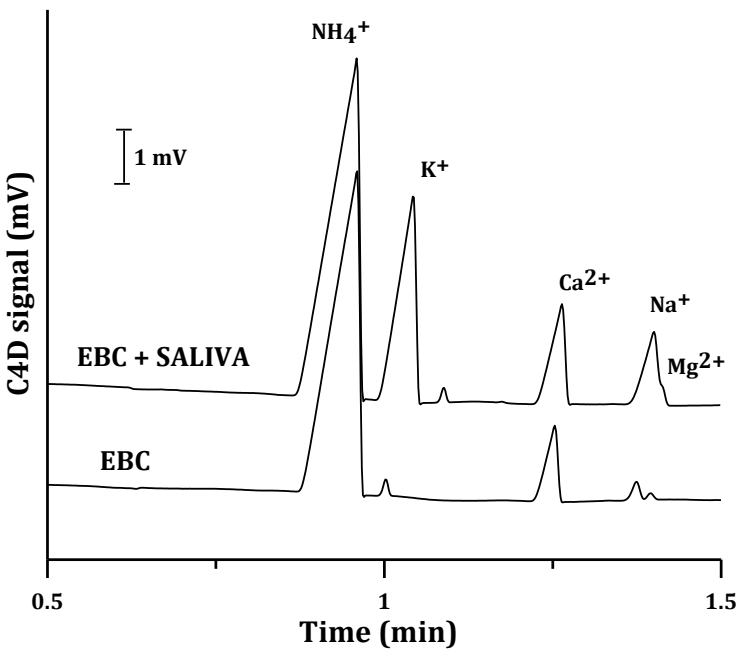

Figure 3: Cationic separation of an EBC sample and an EBC sample spiked with human saliva. BGE: $20 \mathrm{mM}$ MES/His, 2 mM 18-Crown-6, $30 \mu \mathrm{M}$ CTAB. HV: negative $-15 \mathrm{kV}, \mathrm{C} 4 \mathrm{D}$ detection. Injection: hydrodynamic for $30 \mathrm{~s}$ at a height of $10 \mathrm{~cm}$.

\subsection{Day-to-day repeatability of the ionic con- tent of EBC}

In the next part of the study, the day-to-day repeatability of the ionic content of EBC (over the following 5 days) obtained from three healthy persons (\#1, \#2 and \#3) was studied. Samples were collected in the morning, before breakfast, and all volunteers were asked not to drink or eat before the sampling, the only exception was the consumption of tap water. EBC samples were obtained from single exhalations by using the EBC sampler. All samples were analyzed by CE-C4D and peak areas of all ions in the electropherograms were integrated. The resultant peak areas (PA) for selected ions (ammonium, sodium, acetate and nitrite) were plotted against each of the five
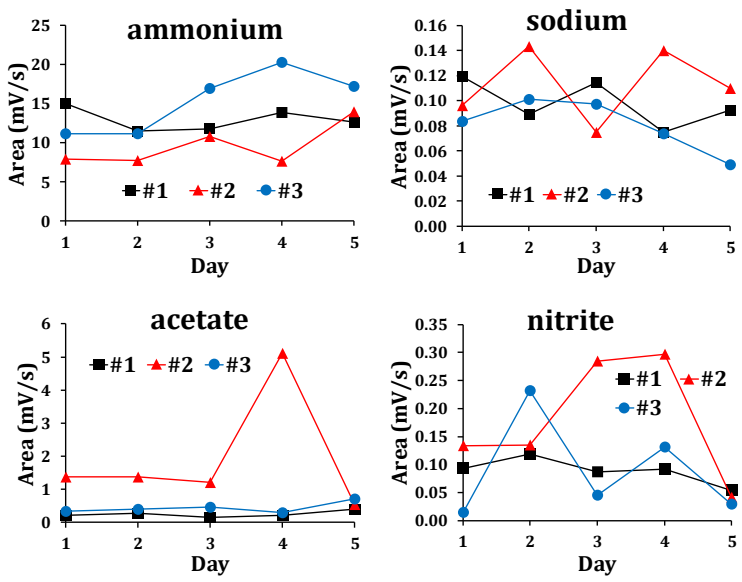

Figure 4: PA of selected ions found in EBC from a day-today study consisting of 5 days. Separation and detection conditions as in Figs. 2 and 3. 


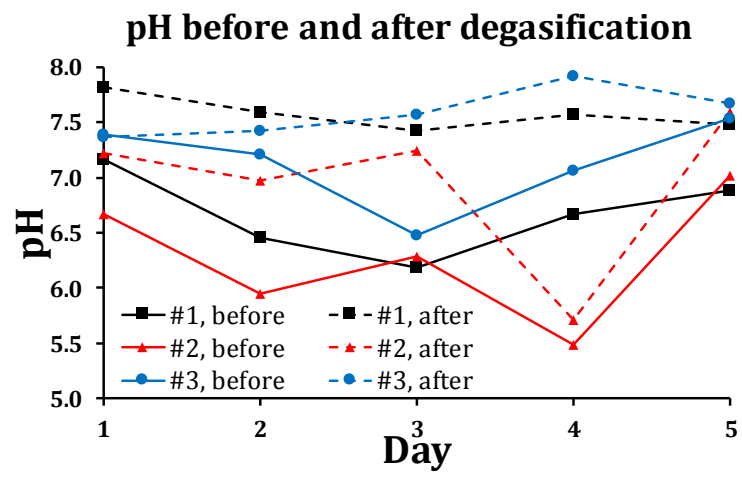

Figure 5: The trend over 5 days in the $\mathrm{pH}$ of EBC samples obtained from three healthy volunteers. The $\mathrm{pH}$ of EBC before (solid line) and after degasification with $\mathrm{N}_{2}$ (dashed line).

days (Fig. 4). From this figure, a sufficient repeatability of all ions present in EBC samples over the five days can be seen. Although the spread might seem large, this is caused mainly by the physiological variability of the ion concentration in EBC.

\subsection{Day-to-day repeatability of the $\mathrm{pH}$ of $E B C$}

Except for cations and anions, which were measured by CE-C4D, other parameters, e.g. exhaled breath volume (measured by spirometry) or the $\mathrm{pH}$ of EBC, can be necessary for standardization and diagnostic purposes $[12,13]$. The $\mathrm{pH}$ of EBC samples was measured and the current experimental setup allowed for $\mathrm{pH}$ measurements to be made from as little as $10 \mu \mathrm{L}$ of EBC. The $\mathrm{pH}$ of EBC obtained from a single exhalation can thus be easily measured. The $\mathrm{pH}$ of EBC samples obtained in the previous section (day-to-day repeatability) was measured before and after degasification with $\mathrm{N}_{2}$ (1.8 atm for 5 mins.), and the resultant data can be seen in Fig. 5. It is known that the degasification of liquids by an inert gas, such as $\mathrm{N}_{2}$, can remove dissolved gases, e.g. $\mathrm{CO}_{2}$ [14]. Our experiments support this premise since an increase in the $\mathrm{pH}$ of all samples was observed after degasification with $\mathrm{N}_{2}$. Moreover, degasification of the EBC samples significantly increased the repeatability of $\mathrm{pH}$ values over the 5 days of the day-to-day study.

\subsection{Other parameters that influence the ionic content of $\mathrm{EBC}$ and the $\mathrm{pH}$}

The influence of various foods, drinks and meals on the ionic content and $\mathrm{pH}$ of EBC was also examined. Two EBC control samples (taken in the morning, before breakfast during which only water could be drunk) were obtained from one healthy person. These samples were compared with the two EBC samples from the same day and after one of the following foods/drinks/meals breakfast, lunch, chocolate, coffee, orange juice, milk, chewing gum or after cleaning teeth with toothpaste or

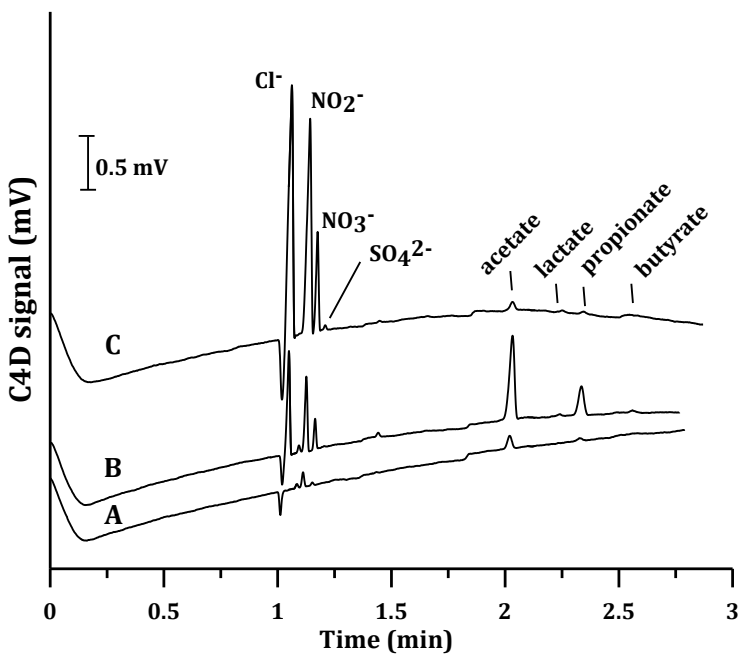

Figure 6: Separation of anions in different EBC samples. EBC samples collected in the morning (A), after the ingestion of orange juice (B), and after chewing a piece of chewing gum (C). BGE: $20 \mathrm{mM}$ MES/His, $2 \mathrm{mM} \mathrm{18-}$ Crown-6, $30 \mu \mathrm{M}$ CTAB. HV: positive $+12.4 \mathrm{kV}$, C4D detection. Injection: hydrodynamic for $20 \mathrm{~s}$ at a height of $12.5 \mathrm{~cm}$.

dentifrice. The time lag between each of the influences and sample collections was 10 minutes. Examples of the separation of anions and cations in EBC samples collected in the morning, after the ingestion of orange juice and chewing a piece of chewing gum are shown in Figs. 6 and 7. Overall, significant differences were found between samples and, therefore, a time lag of at least one

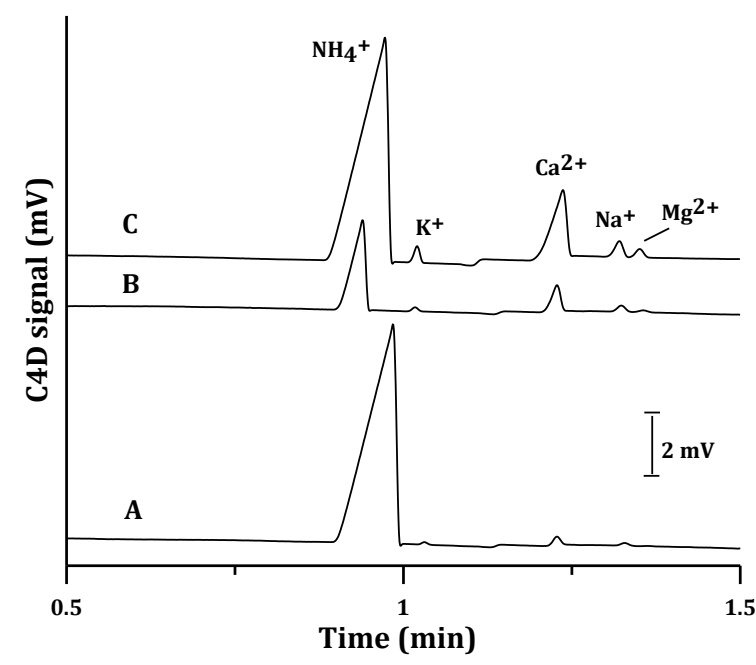

Figure 7: Separation of cations in different EBC samples. EBC samples collected in the morning (A), after the ingestion of orange juice (B), and after chewing a piece of chewing gum (C). BGE: $20 \mathrm{mM}$ MES/His, $2 \mathrm{mM} \mathrm{18-}$ Crown-6, $30 \mu \mathrm{M}$ CTAB. HV: negative $-14.5 \mathrm{kV}$, C4D detection. Injection: hydrodynamic for $20 \mathrm{~s}$ at a height of $12.5 \mathrm{~cm}$. 
hour following the flushing of the mouth with DI water was suggested prior to the EBC collection to obtain a relevant EBC sample.

\section{Conclusion}

In this work, capillary electrophoresis with contactless conductometric detection was used to study the day-today repeatability of the ionic content of EBC. The $\mathrm{pH}$ of EBC before and after degasification with a stream of $\mathrm{N}_{2}$ was studied by a $\mathrm{pH}$ microelectrode over five consecutive days. The influence of various foods and drinks on the ionic content of EBC was investigated and exhibited significant differences between EBC samples. It has been shown that EBC is influenced by various parameters. Therefore, healthy individuals or patients should provide their EBC samples in the morning before breakfast/brushing teeth or at least one hour after consuming any food or drink last followed by flushing of the mouth with DI water.

\section{Symbols}

CE capillary electrophoresis

C4D contactless conductivity detection

CTAB cetyltrimethylammonium bromide

DI deionized

EBC exhaled breath condensate

His L-Histidine

ID inner diameter

MES 2-(N-Morpholino)ethanesulfonic acid

OD outer diameter

\section{Acknowledgement}

The authors acknowledge the financial support from the Ministry of Health of the Czech Republic (Grant No. 17-31945A). Part of this research was conducted under the CEITEC 2020 project LQ1601 with financial support from the Ministry of Education, Youth and Sports of the Czech Republic under the National Sustainability Programme II and with institutional support RVO: 68081715.

\section{REFERENCES}

[1] Shaheen, N. J.; Hansen, R. A.; Morgan, D. R.; Gangarosa, L. M.; Ringel, Y.; Thiny, M. T.; Russo, M. W.; Sandler, R. S.: The burden of gastrointestinal and liver diseases, Am. J. Gastroenterol., 2006 101(9), 2128-2138 DOI: 10.1111/j.1572-0241.2006.00723.x

[2] Vakil, N.; van Zanten, S. V.; Kahrilas, P.; Dent, J.; Jones, R.: The Montreal definition and classification of gastroesophageal reflux disease: A global evidence-based consensus, Am. J. Gastroenterol., 2006 101(8), 1900-1920 DOI: 10.1111/j.15720241.2006.00630.x
[3] Johnston, N.; Ondrey, F.; Rosen, R.; Hurley, B. P.; Gould, J.; Allen, J.; DelGaudio, J.; Altman, K. W.: Airway reflux, Ann. NY. Acad. Sci., 2016 1381, 5-13 DOI: $10.1111 /$ nyas. 13080

[4] Emilsson, O. I.; Gislason, P.; Olin, A. C.; Janson, C.; Olafsson, I.: Biomarkers for Gastroesophageal Reflux in Respiratory Diseases, Gastroenterol. Res. Pract., 20132013148086 DOI: 10.1155/2013/148086

[5] Shimizu, Y.; Dobashi, K.; Mori, M.: Exhaled breath marker in asthma patients with Gastroesophageal reflux disease, J. Clin. Biochem. Nutr., 2007 41(3), 147-153 DOI: 10.3164/jcbn.2007020

[6] Greguš, M.; Foret, F.; Kubáň, P.: Single-breath analysis using a novel simple sampler and capillary electrophoresis with contactless conductometric detection, Electrophoresis, 2015 36(4), 526-533 DOI: 10.1002/elps.201400456

[7] Greguš, M.; Foret, F.; Kubáň, P.: Portable capillary electrophoresis instrument with contactless conductivity detection for on-site analysis of small volumes of biological fluids, J. Chromatogr. A, 2016 1427, 177-185 DOI: 10.1016/j.chroma.2015.11.088

[8] Almstrand, A.-C.; Bake, B.; Ljungström, E.; Larsson, P.; Bredberg, A.; Mirgorodskaya, E.; Olin, A.-C.: Effect of airway opening on production of exhaled particles, J. Appl. Physiol., 2010 108(3), 584-588 DOI: 10.1152/japplphysiol.00873.2009

[9] Greguš, M.; Foret, F.; Kindlová, D.; Pokojová, E.; Plutinsk $\imath$, M.; Doubková, M.; Merta, Z.; Binková, I.; Skřičková, J.; Kubáň, P.: Monitoring the ionic content of exhaled breath condensate in various respiratory diseases by capillary electrophoresis with contactless conductivity detection, J. Breath. Res., 2015 9, 027107 DOI: 10.1088/1752-7155/9/2/027107

[10] Kubáň, P.; Foret, F.: Exhaled breath condensate: Determination of non-volatile compounds and their potential for clinical diagnosis and monitoring. A review, Anal. Chim. Acta, 2013 805, 1-18 DOI: 10.1016/j.aca.2013.07.049

[11] Vitali, L.; Fávere, V. T.; Micke, G. A.: A new method to determine biological sample volume by short end multiple injection capillary electrophoresis: Application in determination of nitrate and thiocyanate in human saliva, J. Chromatogr. A, 2011 1218(16), 2327-2333 DOI: 10.1016/j.chroma.2011.02.035

[12] Vaughan, J.; Ngamtrakulpanit, L.; Pajewski, T. N.; Turner, R.; Nguyen, T.-A.; Smith, A.; Urban, P.; Hom, S.; Gaston, B.; Hunt, J.: Exhaled breath condensate $\mathrm{pH}$ assays are not influenced by oral ammonia, Thorax, 2005 60(1), 27-31 DOI: 10.1136/thx.2003.020602

[13] Kostikas, K.; Papatheodorou, G.; Ganas, K.; Psathakis, K.; Panagou, P.; Loukides, S.: pH in expired breath condensate of patients with inflammatory airway diseases, Am. J. Respir. Crit. Care Med., 2002 165(10), 1364-1370 DOI: $10.1164 / \mathrm{rccm} .200111-068 \mathrm{OC}$ 
[14] Ahmadzai, H.; Huang, S.; Hettiarachchi, R.; Lin, J. L.; Thomas, P. S.; Zhang, Q.: Exhaled breath condensate: a comprehensive update, Clin. Chem. Lab.
Med., 2013 51(7), 1343-1361 DOI: 10.1515/cclm-20120593 